\title{
Notes for the guidance of Regional Advisers
}

\section{Consultant posts for alcohol and drug dependence}

1. The psychiatric services are responsible for a growing number of patients with alcohol or drug problems. Nationally, the facilities for specialised treatment of alcohol or drug misuse are patchy. There is a need for larger units to act as centres of expertise, to stimulate and guide developing services, to treat and advise individual patients, and to promote research. There is also a requirement for consultant psychiatrists to provide special services at local levels for alcohol and drug dependent patients.

2. Regional Advisers are required to obtain advice from the Regional Representative in all specialities that appoint Representatives to regions. Each health region has a Representative for alcohol and drug dependence. Further advice can also be obtained from the Chairman of the Substance Misuse Section.

3. The majority of the consultants working in the dependencies will be general consultants with a special responsibility. Training and experience will have been gained in basic and higher specialist training posts. The consultant will usually be expected to provide at least five sessions for the dependencies. Particularly in major centres of population and academic training, the consultant will likely spend the whole or the majority of his time in the field.

4. A general description of the post should be offered that will include reference to the overall plans for local psychiatric services.

5. Details should be provided of the population that will be served. A reference may be needed to special situations; for example, inner city problems, geographical difficulties in providing a service, and the existing statutory and voluntary facilities.

6. Type of post:

(a) The description should state whether the post is full time or part time, and whether an option is provided.

(b) There is an average requirement for 0.6 wte consultants per 100000 population. Factors influencing the number of consultants required in a locality will be incidence of high social deprivation (which is associated with substance misuse) and, in rural areas, difficulties in relation to accessibility and the time needed for clinical assessment and travel.

Some posts deal only with alcoholic patients, some only with drug dependent patients, while others involve both types of patients. The job description should clearly delimit which of the above categories are required for the post.

The description should therefore specify the area served, the number of sessions required for dependence work, the nature and number of the remaining sessions, and the types of patient and substance problem that would be involved in the dependence work.

It is also helpful to indicate subspeciality duties additional to treatment. Because of the widespread inadequacy of the current services of alcohol, and more particularly for drug misusers, it is probable that an initial appointment of this nature will require the consultant to develop NHS services for the subspeciality and to establish liaison with other treatment agencies. The latter include psychiatrists, general practitioners, physicians (especially in departments of gastroenterology), accident and emergency departments, social services and voluntary organisations. Some of the consultant's time will be spent in the stimulation and guidance of facilities outside the NHS provided by statutory and voluntary services.

(c) Because of the number of persons involved or interested in alcohol and drug dependence, the consultant and supporting staff will require identifled sessions to undertake a training role; the trainees include psychiatrists, general practitioners, other hospital doctors, medical students (if near a university), and the paramedical professions; social workers, probation officers, psychologists and voluntary councillors. An educative role for the general public and for the media is also important. It may also be helpful to allocate sessions for research and planning.

(d) The job description should include a sufficient allocation of time and resources 
for continuing professional development (CPD).

(e) Academic links with university departments should exist and be identified. The links need not be confined to departments of psychiatry. University departments should be asked to furnish for the job description an account of the academic ties.

(f) Other links should also be described, e.g. with social services, health promotion services and voluntary agencies.

(g) Membership on committees and planning groups should be identified.

(h) On call duties require specification.

7. Facilities:

(a) The nature (in-patient, out-patient, daypatient) of the facilities should be described.

An average of three beds per 100000 population should be reserved for the management of substance misuse, with adjustments up or down according to socio-demographic factors and other facilities which might be available. In rural settings, where community support may be thinly spread, relatively greater numbers may require in-patient management. There should be provision for special need categories of patient, such as those with alcoholic brain damage and drug misusers who are HIV-symptomatic.

(b) Their sites should also be outlined.

(c) The number of junior doctors and paramedical staff will be precisely stated. Because of the role the consultant will undertake in training psychiatrists, there is a need for rotation of psychiatric trainees to the consultant. Junior staff may also usefully include trainee general practitioners.
Because of the many social problems of patients, social work input should have been agreed. Treatment conducted or supervised by psychologists is undertaken in many areas, is undergoing rapid development, but is time consuming; for its purpose the service will require specified sessions of a psychologist. At least one community psychiatric nurse is necessary. The number of other nurses depends on the present and anticipated build up of out-patient. day-patient and in-patient services. Access to occupational therapy is required for both day-patients and in-patients. The provision of a proper level of nursing and other staff should not await the development of services but is necessary for the growth of facilities.

A full-time secretary is crucial for the medical staff. The social work nursing and psychology services require additional secretarial assistance.

(d) Office and other facilities that are avallable require specification, keeping in mind the number of disciplines involved in alcohol and drug dependence. Space for teaching is required. Accommodation should be available for meetings by self-help organisations such as Alcoholics Anonymous.

8. Within a health district the responsibility for relevant patients should be delimited between general psychiatrists and the speciality consultant. In the case of an appointment to a regional or subregional unit, the psychiatrists within the districts covered by the unit would continue to undertake the clinical care of many patients with alcohol or drug problems, in view of the number of persons so affected.

\section{Queen's Birthday Honours List}

The following awards were recetved by members of the College in the Queen's Birthday Honours List:

Dr Rosemary Wool CB

Professor Tom Arie CBE

Professor Robert Bluglass CBE

Dr Judy Greenwood OBE

Professor George Brown OBE 